$\begin{gathered}\text { EPiC Series in Education Science } \\ \text { Volume 1, 2017, Pages 505-515 }\end{gathered}$
$\begin{gathered}\text { AUBEA 2017: Australasian Universities Build- } \\ \text { ing Education Association Conference 2017 }\end{gathered}$

\title{
Improving the Student Experience with Learning Analytics in Construction Project Management Courses
}

\author{
P. Saunders, E. Gharaie, A. Chester \& C. Leahy \\ RMIT University \\ peter.saunders@rmit.edu . au; ehsan.gharaie@rmit.edu . \\ au; andrea.chesterarmit.edu.au; \\ cathy . leahyermit.edu . au
}

\begin{abstract}
Learning analytics is an emerging field that has been gaining momentum in higher education. Learning analytics is the analysis and reporting of learner related data. Research has examined the benefits of learning analytics in higher education but there has been limited research conducted about the impact of showing students their own learning data. The aim of this study was to provide students with their own learner data, obtain feedback about the usefulness of this information and investigate if providing learning data leads to an increase in self-efficacy and self-reflection. The sample consisted of 78 students studying construction management, project management, and property and valuation. Students were provided with weekly learner reports that included data about their behaviour in a learning management system, their level of interaction in lectures, and their performance on assessments. A suggested target was provided toward an individualised behaviour goal, as well as comparison with both the contemporary class average and previous class averages. Students completed measures of self-efficacy and self-reflection pre and post intervention and feedback about the reports was obtained through surveys and a focus group. Results showed no significant change in self-efficacy and self-reflection, however, students reported finding the learning analytics reports helpful, believed it helped them reflect on their own learning and wanted to see more analytics in other subjects. Results support the use of learning analytics in the classroom and suggest that they may enhance the student experience.
\end{abstract}

Keywords: Learning Analytics, Higher Education, Construction Project Management 


\section{INTRODUCTION}

Learning analytics has been viewed as having the potential to transform learning and teaching in higher education. Learning analytics is the analysis and representation of data about learners to improve learning (Clow, 2013). The field of learning analytics is related to pre-existing domains, such as educational data mining and web analytics (Prinsloo, Slade \& Galpin, 2012).

Higher education institutions have used learning analytics data to identify and appropriately support students, whether they are at risk, underprepared or high performing (Prinsloo, Slade \& Galpin, 2012). Recent technological advances have seen the advancement of learning analytics, such as predictive analytics (Waller \& Fawcett, 2013) and the development of apps to monitor student behaviour and provide data regarding well-being, mood and academic performance (Wang et al., 2014).

There are numerous pedagogical implications associated with learning analytics. Learning analytics provide staff with a pedagogical device that can be used in a neutral, formative way to help students become more aware of their own learning and to help understand why they may be facing particular challenges. The potential exists to use learning analytics in the classroom to help students engage in their own learning.

Information about student performance or learning behaviour can be collected from a range of different sources. Data has traditionally included student enrolment data, academic records, student surveys, and data from online discussion boards. Data about student behaviour can also be obtained from students' interactions with university learning systems (Aljohani \& Davis, 2012).

Learning management systems (LMS), such as Blackboard and Moodle, attempt to replicate traditional classroom and institutional processes with the inclusion of formal assessments, courses and classes (Rahman and Dron, 2012). The Substitution Augmentation Modification Redefinition model, developed by Puentedura (2011), describes levels of technology integration and how it might impact learning and teaching. The model shows how technologies, such as LMS, may transform and enhance previous educational methods if the technologies are appropriated, implemented and designed. One of the benefits of an LMS is that it can provide built in learning analytics that can be used to monitor student behaviour and provide feedback to educators. Data about students can be gathered objectively and with relative ease. Research has suggested that learning analytics from an LMS may help reduce attrition, show student progress and identify students in need (Arnold \& Pistilli, 2012; Picciano, 2012; Siemens \& Gasevic, 2011). In addition, some studies suggest that student behaviour in an LMS predict academic performance. In their study of nine undergraduate courses in Australia, Gasevic et al. (2014) found that number of logins, resources used and operations performed in discussion forums were significant predictors of academic performance. Despite the positive implications of these findings, there are likely to be moderating variables that impact LMS use and academic performance and the authors note that it is difficult to translate these findings into actionable recommendations for students (Gasevic et al., 2014). Furthermore, other research has found that LMS use does not predict academic success (Broadbent, 2016). It would be beneficial to further examine how LMS use can be used to assist students.

Despite the advances in technology and relative flexibility of most LMS, one of the major limitations of learning management systems is that they do not lend themselves to learner-centric approaches (Rachman \& Dron, 2012). Students are generally not given the opportunity to adapt the LMS to cater to their own learning. Further, the learning analytics offered in the LMS tend to be available to educators but not students. The inability to easily retrieve and adapt data for students in the LMS presents a challenge for the use of learning analytics. Authors have also noted concerns 
associated with learning analytics, including the potential to create a culture of student surveillance rather than empowerment (Slade \& Prinsloo, 2013).

Students' beliefs about their academic capabilities have long been thought to play an important role in their motivation and ability to achieve (Zinmmerman, 1999). In particular, self-reflection and self-efficacy have been found to be important predictors of academic performance. Self-reflection refers to an individual's ability to analyse their own behaviours with outcomes i.e. what actions lead to reactions? Where positive reactions occur, how can we understand and increase the action that led to them? Self-efficacy is an individual's belief that they are likely to succeed in a task (Stajkovic \& Luthans, 1979). Students who have higher self-efficacy are more likely to be confident learners and are more likely to participate, engage and persist with their academic studies (Pajares, 2007). Selfefficacy is a strong predictor of academic achievement and success (Broadbent, 2016; Chemers, Hu \& Garcia, 2001). It is therefore important to understand ways of improving a student's self-efficacy, but integral to doing this is to have them learn about, and reflect on, their own learning behaviours.

Learning analytics have tended to be used and viewed from the educator's perspective. However, there are substantial benefits to directly sharing learning analytics with students (Prinsloo, Slade \& Galpin, 2012). Individual pieces of data may not be inherently useful, but when collected and analysed in cohorts, learning analytics has the power to inform students about how they are progressing, how their learning behaviours compare with other students, as well as information such as learning characteristics of students who are performing at higher levels. When given to students and used as a reflective device, learning analytics may also inform students about how many hours they are spending on learning tasks and how they engage with different types of materials, thus, showing how to maximise learning. Learning analytics can teach students about their own learning behaviours, giving them more insight and agency in their learning.

The purpose of this study was to provide students with personalised data from a range of contexts, including behaviour in an LMS, assessment performance, and interaction in lectures. As well as individual data, students were also provided with class comparison data. This project aimed to use these learning analytics to promote learner self-reflection and self-efficacy. In addition the study sought feedback from students on the perceived value of this data.

\section{METHODOLOGY}

Students in a first-year undergraduate construction management course at a large Australian university were invited to participate in the research. Of the 151 students enrolled in the course, 78 students ( 23 female, 53 male and 2 other) agreed to participate in the study. Participants ranged in age from 18 to 25 .

Learner data reports were provided by email at the end of each week throughout the 12-week semester. The learner data was collected from three different sources: LMS, lecture participation and weekly assessment performance (described in detail below). Student self-efficacy and self-reflection were measured at the beginning and end of the semester.

An action research approach was used (Kemmis \& McTaggart, 1988). A cyclical (plan, act, observe, reflect) and participative model was adopted, with students actively engaged to help construct and improve the learner reports throughout the semester. ' 
Ethics approval to conduct the study was obtained by the Human Research Ethics Committee (HREC).

\subsection{LMS user of learner data}

The LMS was used in this course to provide learning resources, including readings and lecture recordings as well as assessment tasks, rubrics and guides. Students submit their assessment tasks via the LMS.

The research team extracted learner data available on the LMS including total number of times students have accessed different areas in the LMS and the breakdown of total hours per week. This data was presented to students visually as individualised data. This information provides data about student behaviour but it does not indicate the level of engagement with the material. The class average was also provided for comparison. A sample LMS report is shown in figure 1.

\section{How am I using Blackboard?}

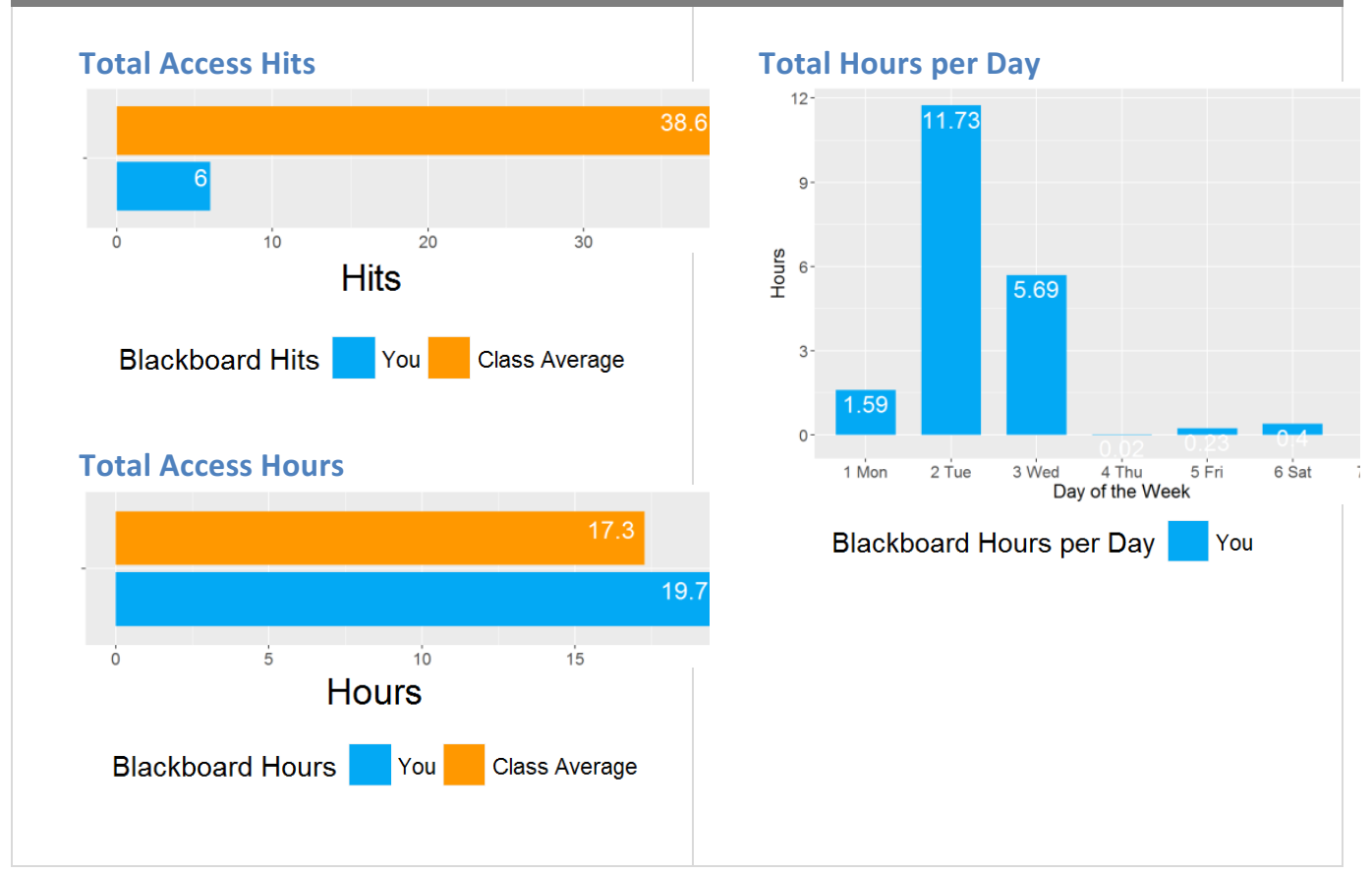

Figure 1: Sample LMS user data report

\subsection{Lecture participation data}

The second source of learner data was lecture participation. In order to create an interactive learning environment, each lecture was broken down to smaller topics or concepts. Each concept concluded with a class activity. Students reported the result of their activity using a real time polling system. Turningpoint was used to create the real-time polling and Responseware was used for collecting the student responses and collated responses were shared in the lecture. Individual student 
responses were collected, collated, and reported back to students with class average comparisons. Figure 2 shows a sample of the lecture participation report. 


\section{How have I interacted with the in lecture questions?}

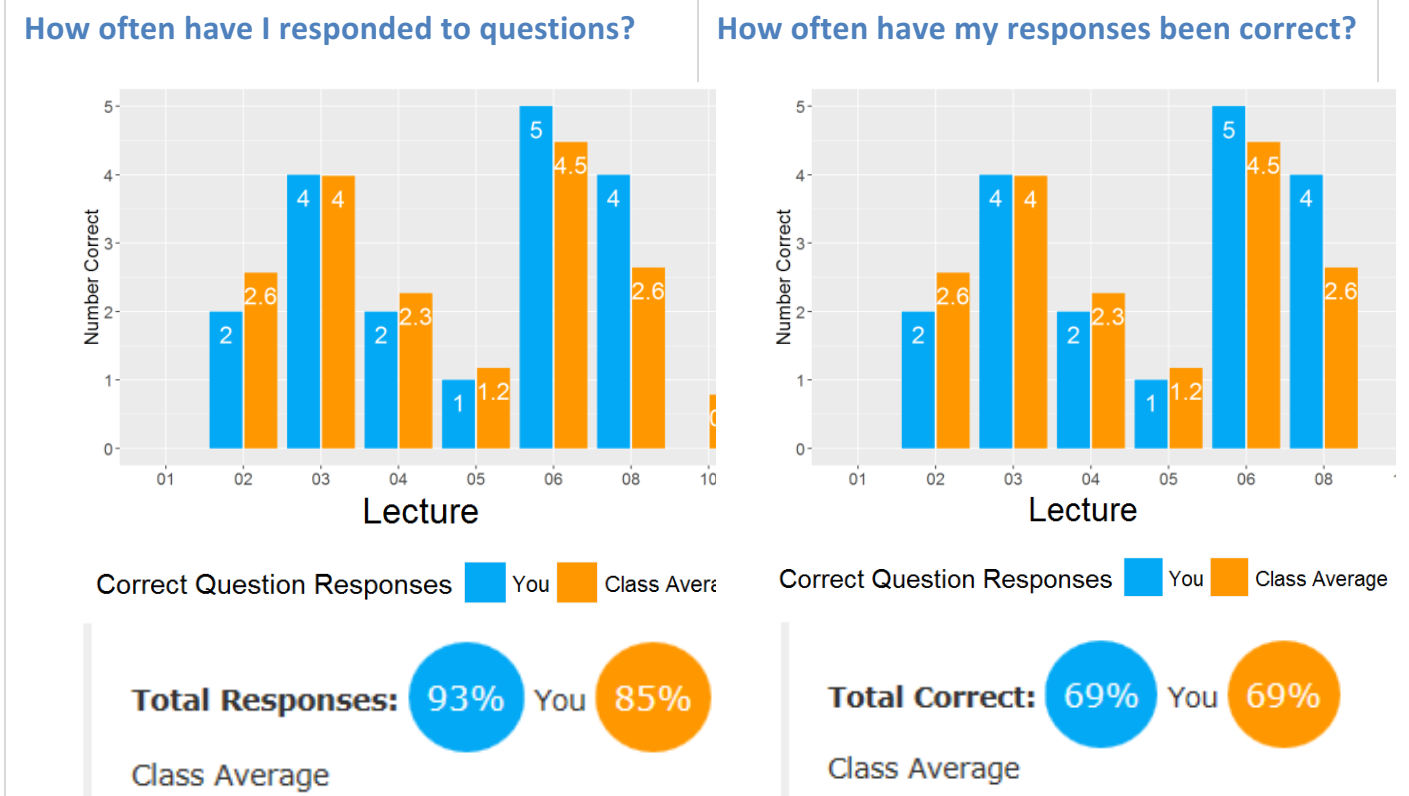

Figure 2: Same lecture participation report

\subsection{Weekly assessment performance}

The third source of data was individual weekly assessments results. One of the assessments in this course was a continuous formative task. Students were required to apply their learning on the weekly tasks and submit their work every week. These tasks were marked and the feedback and marks were provided to the students by the end of the week. Figure 3 shows a sample of the weekly student performance report.

The data provided to the students included four components:

I. Student's weekly mark: this was produced based on the lecturer's assigned mark for the weekly assessment task.

II. Class weekly average mark

III. The weekly average mark of the previous cohort: this included the average mark for the weekly assessment task from the class from the previous year.

IV. Personal target: students were asked at the beginning of the semester to set a target grade for the course as a whole. Students were reminded of this target in their weekly reports. 

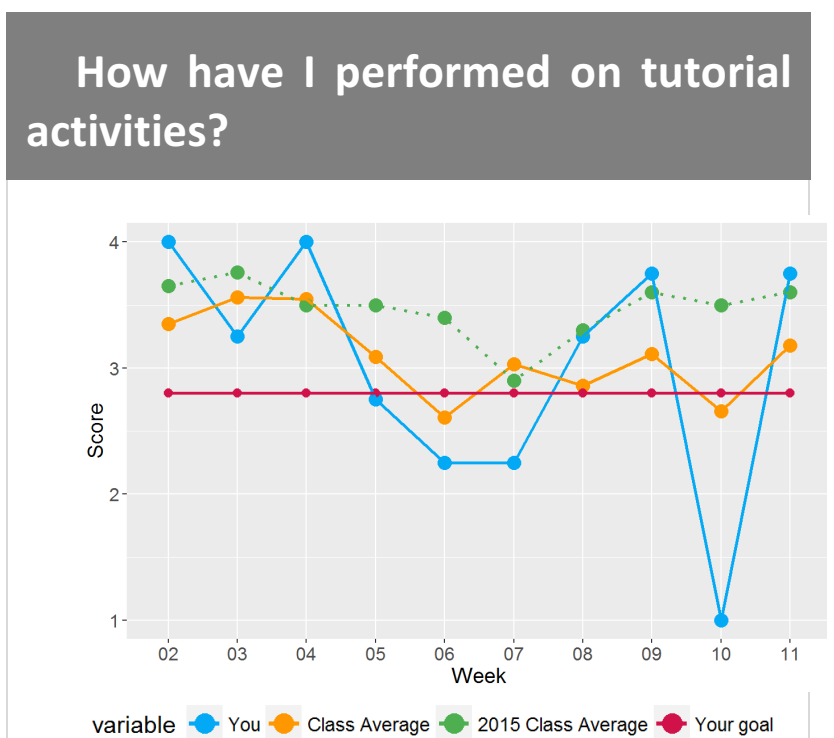

Your goal is

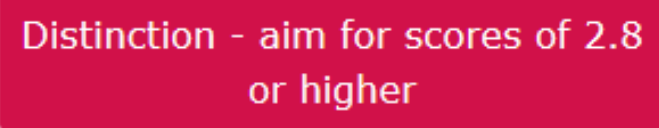

On track with your goal

Figure 3: Sample weekly assessment report

\subsection{Self-efficacy and self-reflection}

Students completed the Generalised Self Efficacy Scale (Schwarzer \& Jerusalem, 1995) and Self-Reflection and Insight Scale (Grant et al, 2002) online at the beginning and end of the semester. Both measures are appropriate to use in an academic context. The Generalised Self-Efficacy Scale consists of 10 items designed to assess optimistic self-beliefs with a variety of difficult demands in life. Research has found that the scale is psychometrically sound (Schwarzer \& Jerusalem, 1995).

The Self-Reflection and Insight Scale was designed to measure private self-consciousness, selfreflection and insight. The scale has 20 items and responses are provided on a six-point Likert scale ( $1=$ strongly disagree, $6=$ strongly agree). The scale has been found to correlate positively with other self-reflection scales and test-retest reliability has been found to be .78 (Grant, Franklin and Langford, 2002). 


\subsection{Student feedback on and use of the learner reports}

Throughout the semester, students were invited to provide feedback to the research team. At the end of the teaching period students were also invited to complete a survey evaluating the learner reports. Students were invited at the end of the semester to attend focus groups to share their experience in an in-depth conversation with a member of the research team.

During the teaching period, the research team monitored learner report emails to determine if they had been opened. Although this is not a measure of engagement, it provided the team with information about how consistently students were accessing the reports.

\section{RESULTS}

Results of the end of semester survey showed that students valued the learner reports and these reports were perceived to have a positive impact on their learning. In total, $78 \%$ of students rated the learner data reports as helpful and the same number rated the reports as useful in reflecting on their own learning. The majority of students $(80 \%)$ reported that they would like to see similar learner data reports in their other classes. One suggestion by the students was that they would like to see a learner report that incorporated data from all of their courses, providing a holistic picture of their academic progress.

Most of the students found the learner reports helpful. $44 \%$ of students rated the learner data reports that they received as 'very helpful, 33\% of students rated the data reports as 'somewhat helpful,' $11 . \%$ of students rated the helpfulness of the reports as 'neutral' and $11 \%$ of students rated them as 'somewhat unhelpful.' These findings suggest that, overall students found the reports helpful.

Of the information they received, students reported that LMS hits were the least useful because they were not as informative as the other pieces of data.

A small percentage of students (11\%) did not find the learner reports helpful. Further interrogation revealed that these students were not progressing well in the course and were either failing or just passing. Follow up conversations with these students indicated that the learner report was not perceived to offer any new information - these students already knew they were not doing well. In the focus group students suggested that they would have liked suggestions for how to improve and links to resources and support. They also recommended that the reports form the basis for a follow up conversation with teaching staff focused on suggestions for improvements in their studies.

The majority of students (78\%) opened their emails about learner data and most of the students $(65 \%)$ reported that they were opening their reports on a weekly basis. This suggests there was a considerable interest in students seeing their learner's data. The anecdotal conversations with the students throughout the research implementation phase also confirmed this interest.

While students appeared to appreciate the learner data and perceived it as useful for their learning, comparison of scores on the Generalised Self Efficacy Scale and Self-Reflection and Insight Scale revealed only small improvements over time. Neither was significant. 
Students reported that they felt that self-reflection would have increased if the reports had been discussed in class. Students felt that discussion in class would have provided a deeper understanding of the reports and a greater chance to interpret what they meant.

Students reported that they liked being able to see how they compared to other students as it gave a better sense of their performance and they could track when other students found certain assessments difficult. Particularly, this comparison is helpful for the first year and exchange students who have not yet created their networks. The reports provide them with a benchmark to that they can compare themselves.

\section{CONCLUSIONS}

Learning analytics has been viewed as having the potential to change learning and teaching in higher education. Higher education institutions have used learning analytics primarily to identify and address the challenges the students face. These applications of learning analytics are predominantly developed from an educator's perspective. However, there are potential benefits to directly sharing analytics with students.

This research investigated the use of learning analytics to enhance the student experience. A large cohort of students in a construction project management course were chosen for the study. The learner's data were analysed and fed back to students. Student feedback was sought throughout the project implementation and at the end of the semester through student surveys. A focus group was held to receive in depth feedback from students.

Overall, the results indicated that students valued the learner reports they received and felt that it had a positive impact on their learning. This is an important finding as it demonstrates that students are interested in their own learning behaviour and that learning analytics may be useful for students as well as staff. Based on the current findings learning analytics may improve the student experience.

Most students reported that the learner reports helped them reflect on their own learning and the majority students reported that they would like to see similar learner data reports in their other classes. These findings confirm the usefulness of such reports and demonstrate that, when used appropriately, learning analytics has the potential to help students engage in their own learning.

The results did not show any significant changes in self-efficacy or self-reflection. The information provided to students did not increase their belief in their ability to achieve. There are a number of potential reasons for this. The information provided to the students did not provide any tips, suggestions or ideas about what to do with the information they received. It may have been beneficial to have given students direction about what to do to help change their behaviour. For example, students with low scores on assessments could have been provided with links to services or tips on how to help improve their learning or scores. It may have also been that students did not process the information in the learner reports. The only data we have available is about how often the emails were accessed. By itself, this information is limited and tells us little about how students engaged with the material. It may have been beneficial to have discussed the learner reports in class to help strengthen student understanding and engagement with the reports. 
The research has demonstrated that learning analytics can enhance the learning experience. Students suggested a better analytics report in which a single report integrates all their analytics from all courses.

To our knowledge, this is the first study that has actively shown students their own learner data. Providing learner's data to the learner is a new area that creates new dynamics in classrooms. Participants of this study suggested follow up conversations with the instructor after they received their reports. This opens new areas of work for student experience enhancement and introduces new dynamics to the classrooms that require further investigation.

\section{REFERENCES}

Aljohani, N, \& Davis, H. (2012). 'Learning analytics in mobile and ubiquitous learning environments'. Presented at the 11th World Conference on Mobile and Contextual Learning.

Arnold, K, \& Pistilli, M. (2012). 'Course Signals at Purdue: Using Learning Analytics to Increase Student Success', LAK '12 Proceedings of the 2nd International Conference on Learning Analytics and Knowledge.

Broadabent, J. (2016). Academic success is about self-efficacy rather than frequency of use of the learning management system. Australasian Journal of Educational Technology, Vol 32 (4).

Chemers, M., Hu, L., \& Garcia, B. (2001). Academic self-efficacy and first year college student performance and adjustment. Journal of Educational Psychology, Vol 93(1), pp. 55-64.

Clow, D (2013). 'An overview of learning analytics'. Teaching in Higher Education, Vol. 18(6) pp. 683-695.

Gasevic, D., Kovanovic, V., Joksimovic, S., \& Siemens, G. (2014). Where is research on massive open online courses headed? A data analysis of the MOOC Research Initiative. The International Review of Research in Open and Distributed Learning, Vol. $15(5)$.

Kemmis, S. \& McTaggart, R. (1988). The action research planner. Victoria: Deakin University.

Pajares, F. (2007). Culturalizing educational psychology. In F. Salili \& R. Hoosain (Eds.), Culture, motivation, and learning (pp. 19-42). Charlotte, NC: Information Age.

Picciano, A.G. (2012). The evolution of big data and learning analytics in American higher education. Journal of Asynchronous Learning Networks, Vol 16(4).

Prinsloo, P., Slade, S., \& Galpin, F.A.V. (2011). 'Learning analytics: challenges, paradoxes and opportunities for mega open distance learning institutions'. Paper presented at 2nd International Conference on Learning Analytics and Knowledge (LAK12), Vancouver.

Puentedura, R. (2014). 'Building transformation: An introduction to the SAMR model' [Blogpost].Retrievedfrom http://www.hippasus.com/rrpweblog/archives/2014/08/22/BuildingTransformation AnIntro ductiontoSAMR.pdf

Rahman, N. \& Dron, J. (2012). 'Challenges and opportunities for learning analytics when formal teaching meets social spaces'. Proc. 2nd Int. Conf. on Learning Analytics \& Knowledge. New York: ACM.

Siemens, G., \& Gasevic, D. (2011). Proceedings of the 1st conference on Learning Analytics and Knowledge. New York, NY: ACM

Slade, S., \& Prinsloo, P. (2013). Learning analytics: Ethical issues and dilemmas. American 
Behavioral Scientist, Vol 57 (10), pp. 1510-1529.

Stajkovic, A., \& Luthans, F. (1979). Self-efficacy and work related performance: A metaanalysis. Psychological Bulletin, Vol 124 (2), pp. 240-261.

Waller, M. \& Fawcett, S. (2013). 'Data Science, Predictive Analytics, and Big Data: A

Revolution That Will Transform Supply Chain Design and Management'. Journal of Business Logistics, Vol. 34 (2) pp. 77-84.

Wang, R., Chen, R., Chen, F., Chen, Z., Chen, F., Tianxing, L, Harari, G., Tignor, S., Zhou, X., Ben-Zeev, D., \& Cambell, A. (2014). 'StudentLife: Assessing Mental Health, Academic

Performance and Behavioral Trends of College Students using Smartphones'. In Proceedings of the ACM Conference on Ubiquitous Computing.

Zimmerman, B. J. (1999). Self-efficacy: An essential motive to learn. Contemporary Educational Psychology, Vol 25 pp 82-91. 